\title{
A biopolítica dos corpos na sociedade de controle
}

Regina Baracuhy (UFPB)

Tânia Augusto Pereira (UFPB)

\section{Resumo}

Neste artigo, refletimos sobre a biopolítica do corpo através dos efeitos de sentidos produzidos pelos mecanismos de saber/poder no discurso do cuidado de si e sobre como os dispositivos disciplinares e de controle agem sobre o corpo apresentado na mídia.

Palavras-chave: biopolítica; corpo; controle. 


\section{Palavras introdutórias}

Com base nas concepções foucaultianas sobre a normatização do corpo, discutiremos aqui sobre o corpo inserido nas sociedades disciplinar e de controle. O que Foucault compreendeu por corpo não é sistematizado facilmente. Mesmo assim, podemos extrair, especialmente a partir de Vigiar e Punir, o significado atribuído ao corpo em sua obra. Para isso, expomos, primeiramente, algumas relações entre corpo e poder disciplinar. Em seguida, discutimos o corpo dentro da sociedade de controle, abordando questões discutidas na contemporaneidade, dentre as quais a exposição espetacularizada do corpo na mídia.

Para Foucault, o corpo é ao mesmo tempo um invólucro e uma superfície que se mantém ao longo da História. Ao contrário do sujeito que não existe a priori, que é constituído nas relações de poder-saber, o corpo em Foucault preexiste como superfície e é transformável, moldável por técnicas disciplinares. Em algumas das inúmeras entrevistas dadas por Foucault, ele afirmou que, embora estivesse preocupado em fazer uma história do sujeito moderno, ou seja, uma história da subjetivação, ele também estava preocupado com a história do corpo. Deste modo, concomitantemente à história do sujeito moderno, Foucault fez uma história política do corpo. Essa preocupação foucaultiana com o corpo tem dado interessantes frutos. Vários trabalhos exploram a ação que sofre o corpo pelas técnicas de poder presentes em instituições como escolas, hospitais, prisões, dentre outras. As influências das ideias foucaultianas podem ser encontradas em estudos históricos e em abordagens sobre o corpo na sociedade contemporânea (COURTINE, 2008; VIGARELLO, 2006).

A modernidade trouxe consigo todo um conjunto de procedimentos discursivos e institucionais sobre a educação do corpo. Grande parte da obra foucaultiana foi dedicada a compreender um sistema de exercícios corporais que seriam a própria expressão do poder na modernidade. Para Foucault, o corpo é a peça central sem a qual o poder não tem condições de ser exercido. Segundo ele, modernidade e "disciplinarização" do corpo são correspondentes. Ao descrever o funcionamento da sociedade moderna, ele desvendou o funcionamento de uma série de dispositivos disciplinares, presentes no interior das instituições, que tomaram o corpo como objeto de sua ação.

Foucault considera o sujeito histórico e constituído pelos acontecimentos discursivos e práticos. Ele problematiza a questão do sujeito em sua relação com o saber-poder, relaciona o poder à construção do verdadeiro de uma época e mostra que a verdade é uma construção histórica. O autor relaciona também o poder ao corpo, visto que sobre o corpo são impostas proibições e obrigações dos sujeitos, tornando-o alvo de controle exercido cotidianamente na vida dos sujeitos. 
No século XX, segundo Foucault (2005, p. 301), é relevante a importância da Medicina, "dado o vínculo que estabelece entre as influências científicas sobre a população e sobre o corpo". A Medicina é um saber-poder que incide ao mesmo tempo sobre o corpo e sobre a população e que tem efeitos disciplinares e regulamentadores. A norma é o que pode tanto se aplicar a um corpo que se quer disciplinar quanto a uma população que se quer regulamentar.

Vista por Foucault como uma tecnologia de poder, a biopolítica vai implantar mecanismos que têm funções bem distintas das funções que eram as dos mecanismos disciplinares. Nos mecanismos implantados pela biopolítica,

"vai se tratar, sobretudo, é claro, de previsões, de estimativas estatísticas, de medições globais [...]; de intervir no nível daquilo que são as determinações desses fenômenos gerais [...]. Vai ser preciso modificar, baixar a morbidade; vai ser preciso encompridar a vida; vai ser preciso estimular a natalidade" (FOUCAULT, 2005, p. 293).

O poder repressor e punitivo, descrito por Foucault, dá lugar à regulamentação da vida, tem a capacidade de produzir alguma coisa relacionada à sua manutenção, de acordo com a liberdade de escolha do sujeito. É a dimensão biopolítica da sociedade de controle, uma forma de poder que rege e regulamenta a vida, assimilando-a e reformulando-a. Trata-se do poder da vida e não sobre a vida.

O aparecimento do biopoder sobre o homem enquanto ser vivo gera um poder contínuo, científico, que é o poder de fazer viver. Tudo isso originou duas séries: 1) corpo-organismo (disciplina no corpo individual); 2) população- processos biológicos (regulamentação da vida e da morte). Na opinião de Foucault,

o poder é cada vez menos o direito de fazer morrer e cada vez mais o direito de intervir para fazer viver, e na maneira de viver, e no 'como' da vida, a partir do momento em que, portanto, o poder intervém, sobretudo nesse nível para aumentar a vida, para controlar seus acidentes, suas eventualidades, suas deficiências [...] (FOUCAULT, 2005, p. 295).

Ao governar os sujeitos para que tenham uma vida melhor, com saúde e mais longa, a biopolítica faz com que eles produzam mais para a sociedade. O sujeito tem que ser saudável para que seja produtivo socialmente. Desta forma, o poder também é positivo.

$\mathrm{Na}$ atualidade, é possível identificar a sobreposição de três dispositivos de poder na sociedade. O primeiro deles, magistralmente descrito por Foucault no livro Vigiar e Punir, é o disciplinar. Ele incide sobre a otimização do corpo em termos de um sistema de recompensas em vista de condutas almejadas e de vigilância e correção, para a prevenção ou correção de comportamentos indesejáveis. Ele ainda pode ser observável em instituições se- 
miabertas como escolas, empresas, hospitais, como também nas famosas instituições de confinamento, caso dos manicômios e prisões. Ao se dirigir à superfície corporal, esses dispositivos proporcionam uma ortopedia moral e a constituição de um indivíduo normalizado segundo os imperativos morais e até mesmo mercadológicos.

O segundo dispositivo é o da segurança, que promete atuar na preservação e no cuidado da vida de uma população biologicamente determinada exigindo, em troca, a restrição de suas liberdades, a obediência a suas normativas e o pagamento adequado de seus impostos. Essa proteção em função dos riscos e perigos internos ou externos possui um elevado ônus, posto que, muitas vezes, está embutida a anuência dos cidadãos à atuação extralegal do Estado e de seus mecanismos diante de outras populações potencial ou realmente consideradas perigosas.

O terceiro é aquele dispositivo que não incide, principalmente, no corpo ou, enfaticamente, na vida biológica, mas opera ao nível do controle das mentes, suas aspirações e desejos. Em sociedades mais desenvolvidas, entre as quais o declínio do trabalho material é acompanhado da ascendência do trabalho imaterial, a planta industrial é sucedida da ampliação das organizações transnacionais, muitas delas virtuais, como o Google, cada vez mais as mentes estão em conexão entre si. Daí ser fundamental a criação de sonhos e desejos, dominar e controlar a arte do possível, delimitar as situações nas quais pensamos atuar livremente e assim por diante.

Importante é salientar que esses três dispositivos atuam conjuntamente, ainda que seja possível mostrar que no recrudescimento da industrialização houve atuação enfática da disciplina; na formação e consolidação dos Estados nacionais, a acentuada operacionalidade do dispositivo da segurança; e nas sociedades pós-industriais e de serviços, marcadas pela decisiva influência da realidade virtual engendrada pela automação dos processos industriais e dos imperativos midiáticos sobre a política e as ideologias, a predominância dos dispositivos de controle.

\section{Corpo e poder disciplinar}

A sociedade disciplinar se instaura a partir do início do século XVIII (FOUCAULT, 2005), compreendendo todos os dispositivos que regulam hábitos e comportamentos, com objetivos de assegurar a obediência às instituições disciplinares que organizam o campo social. As estratégias utilizadas pela sociedade disciplinar eram centradas no corpo. As tecnologias disciplinares se destinavam a todos os sistemas de vigilância ou instituições disciplinares: a prisão, a fábrica, o asilo, o hospital, a escola, entre outras. Foucault assinala que, no século XIX, o poder assume outro paradigma - o biopoder -, que se caracteriza como um poder exercido por máquinas que organizam o "cérebro e os 
1 A noção de espetáculo, desenvolvida por Guy Débord (1997), permite-nos refletir sobre a natureza das representações de corpo na sua apresentação contemporânea. $\mathrm{O}$ corpo contemporâneo ocupa um lugar central, e nas mídias se torna mais explicitamente um corpo-espetáculo, esta construção se articula fortemente com o consumo: é o surgimento do corpo-mercadoria. E o espetáculo é o momento em que a mercadoria ocupa totalmente a vida social (DEBORD, 1997). corpos", um poder responsável não só pelo corpo individual, mas pela vida da população. O poder que toma por objeto a vida em duas funções nas sociedades modernas: "a 'anatomo-política' e a 'biopolítica' e as duas matérias nuas, um corpo qualquer, uma população qualquer" (DELEUZE, 1992, p. 80).

Foucault interpretou o corpo como uma superfície para o exercício de relações de poder, como um "caminho" para a subjetivação. Na opinião de Dreyfus e Rabinow (2010, p. 125), "um dos maiores empreendimentos de Foucault foi sua habilidade em isolar e conceituar o modo pelo qual o corpo se tornou componente essencial para a operação de relações de poder na sociedade moderna".

Para o filósofo francês, o corpo também é uma interpretação dependente de determinado "olhar", ou seja, o corpo terá diferentes valores, dependendo de quem olha e do lugar de onde ele é olhado. Assim, o valor do corpo depende do lugar que ele ocupa. Essa percepção de Foucault (2007) sobre o corpo pode ser ilustrada com a análise que ele faz da tela de Velásquez "As meninas", no início do livro As palavras e as coisas. Essa tela retrata o próprio Velásquez pintando um quadro e algumas pessoas ao seu lado observando o modelo que está posando para o pintor, mas que, no entanto, não aparece na tela. Simultaneamente, o artista não pode ver a si mesmo e o objeto de sua representação. Da mesma forma, só podemos olhar para nosso próprio corpo através do olhar do outro e foi assim que Velásquez se retratou, através do olhar do outro. Com isso, Foucault (2007) afirma que todo olhar "já é uma interpretação", uma posição, um lugar de poder.

Que relação pode ser estabelecida entre o corpo e a análise foucaultiana sobre a tela de Velásquez? O corpo é sempre uma interpretação e o olhar interpretativo que o sujeito lança sobre seu corpo depende do olhar lançado pelo outro sobre esse mesmo corpo. Na contemporaneidade, a busca incessante da mulher pela imagem de um corpo "perfeito" reside no desejo de capturar o olhar do outro para o seu corpo. Tendências exibicionistas alimentam as novas modalidades de construção do corpo, numa "espetacularização do eu ${ }^{1}$ ", que visa à obtenção de um efeito: o reconhecimento nos olhos do outro e, sobretudo, o cobiçado fato de ser visto. Nesse contexto, a subjetividade é estruturada em função da superfície visível do corpo, que se torna um espaço de criação e um campo propício para a expressão do que cada um é.

Os processos de subjetivação, por meio das relações de poder-saber, como descritas e analisadas por Foucault, atuam sobre o corpo do indivíduo através de técnicas disciplinares, ou seja, por meio do disciplinamento e governo do corpo. As novas formas de subjetivação cada vez mais se relacionam com os modelos idealizados de corporeidade. O culto à magreza e a rejeição dos corpos fora dos padrões dominantes se engajam aos discursos contemporâneos de disciplinamento e de controle dos corpos 
femininos como forma de reafirmar as relações de poder. Assim, possuir um corpo magro, atualmente, está relacionado, também, à questão simbólica do "poder".

Portanto, a sociedade do consumo e do espetáculo, na qual as imagens de mulheres belas, felizes e bem-sucedidas estão sempre em "cartaz", produz um cenário perfeito para que o sujeito feminino deseje transformar seu corpo para corresponder ao desejo cultural e assim garantir um lugar no palco desse espetáculo e atrair o olhar do outro.

Os dispositivos disciplinares contemporâneos utilizam a vigilância fundada em saberes racionais e normativos. Estes "saberes" sempre visam uma maior eficiência do corpo, mais saúde, bem-estar, longevidade etc. Isso torna a vigilância algo desejado e não desprezado. Esta é uma grande astúcia da sociedade de controle: o poder controlador passa a ser desejado como algo positivo e prazeroso.

Foucault reforça a produtividade do poder e afirma que ele não é sinônimo de repressão, nem pode ser visto como um produto exclusivo do Estado. Segundo o filósofo,

se o poder só tivesse a função de reprimir, se agisse apenas por meio da censura, da exclusão, do impedimento, do recalcamento, à maneira de um grande superego, se apenas se exercesse de um modo negativo, ele seria muito frágil. Se ele é forte, é porque produz efeitos positivos no nível do desejo [...] e também no nível do saber. O poder, longe de impedir o saber, o produz. Se foi possível constituir um saber sobre o corpo, foi através de um conjunto de disciplinas militares e escolares (FOUCAULT, 2008, p. 148-9).

$\mathrm{Na}$ afirmação seguinte, a ideia da positividade do poder é reforçada por ele:

Temos que deixar de descrever sempre os efeitos de poder em termos negativos: ele 'exclui', 'reprime', 'recalca', 'censura', 'abstrai', 'esconde'. Na verdade, o poder produz: ele produz realidade; produz campos de objetos e rituais de verdade. $\mathrm{O}$ indivíduo e o conhecimento que dele se pode ter se originam nessa produção (FOUCAULT, 2009, p. 161). [Grifos do autor]

O micropoder não tem uma ação exclusivamente negativa, ele pode ser também exercido de forma construtiva. Positivamente, ele produz comportamentos e corpos através de classificações, normatizações e adestramentos. Podemos exemplificar a produtividade do poder com a questão do corpo. Provavelmente, em nenhuma época se falou tanto em corpo como na contemporaneidade. São manuais de conduta, de como alcançar um corpo propagado espetacularmente pela mídia. Há um grande aparato científico em torno do corpo. No campo dermatológico, muitos jovens, desde os 20 anos, visitam regularmente o dermatologista para evitar os efeitos do envelhecimento. Assim, as rugas que surgiriam aos 50 anos são prevenidas precocemente. Ao serem 
incentivados a praticarem determinados comportamentos, estes jovens produzirão corpos plenamente previsíveis e adestrados.

Apesar das vantagens dos saberes normativos, não podemos ignorar o objetivo desses saberes de produzir "corpos dóceis"; corpos submetidos a um regime de poder. Segundo Foucault (2009, p. 118), "esses métodos que permitem o controle minucioso das operações do corpo, que realizam a sujeição constante de suas forças e lhes impõem um relação de docilidade-utilidade, são o que podemos chamar as 'disciplinas'".

No livro Vigiar e Punir Foucault (2009) expõe o funcionamento do "modelo carceral" na sociedade contemporânea de forma mais explícita. Ele resgata o Panoptikon², estrutura arquitetônica idealizada pelo filósofo e jurista inglês Bentham (1748-1832), para simbolizar o poder disciplinar. As disciplinas se manifestam em sua forma pura e originária na prisão, especialmente na utopia benthaminiana da prisão perfeita, em que o regime de vigilância ocorre de modo ininterrupto e invisível. Dessa maneira, os prisioneiros não sabem "quando" estão sendo vigiados e por isso comportam-se constantemente como se estivessem sendo vigiados. Neste aspecto reside a genialidade e a perversidade do sistema panóptico: mesmo que nenhum vigia esteja na torre, os prisioneiros agem como se estivessem sendo vigiados.

$\mathrm{Na}$ concepção de Foucault, o panóptico é o dispositivo que melhor caracteriza o poder disciplinar posto ser ele pensado como um sistema arquitetural constituído de uma torre central e um anel periférico que permite a quem se posiciona no centro visualizar tudo e a todos sem que seja visto. Isso faz com que aqueles que são vigiados tenham sempre a sensação de que estão sendo observados, de modo que se pode chegar ao momento em que a consciência da vigilância faz com que seja desnecessária uma vigilância extensa e objetiva. $\mathrm{O}$ panóptico de Bentham seria "o princípio geral de uma nova 'anatomia política' cujo objeto e fim não são a relação de soberania, mas as relações de disciplina" (FOUCAULT, 2009). Princípio este que, ao aplicar o mecanismo da disciplina, possibilita a construção de um novo tipo de sociedade que se alinha a um modo de aplicação disciplinar. Como bem discrimina Foucault, temos duas imagens da disciplina.

Num extremo, a disciplina-bloco, a instituição fechada, estabelecida à margem, e toda voltada para funções negativas: fazer parar o mal, romper as comunicações, suspender o tempo.

2 Edifício circular em que cada prisioneiro ocupa uma cela, totalmente visível para quem estiver na torre de vigilância situada no centro da construção. Os vigilantes da torre podem ver tudo sem ser vistos pelos prisioneiros nas suas celas.
No outro extremo, com o panoptismo, temos a disciplina-mecanismo: um dispositivo funcional que deve melhorar o exercício do poder tornando-o mais rápido, mais leve, mais eficaz, um desenho das coerções sutis para uma sociedade que está por vir. O movimento que vai de um projeto ao outro, de um esquema da disciplina da exceção ao de uma vigilância generalizada, repousa sobre uma transformação histórica: a extensão progressiva dos dispositivos de disciplina ao longo dos séculos XVII e XVIII, sua multiplicação através de todo 
o corpo social, a formação do que se poderia chamar grosso modo a sociedade disciplinar (FOUCAULT, 2009, p. 184).

Baseado no panoptismo, o poder disciplinar estabelece uma nova forma de exercício de poder: a vigilância invisível que permite classificar, qualificar e punir. Ao se debruçar sobre as radicais modificações de um poder soberano para as sutis técnicas de poder disciplinar, a partir do século XVII até o século XIX, Foucault mostra como o sujeito deixa de ser supliciado e passa a ser assujeitado ao poder soberano.

A maneira como o poder se transforma entre o final do século XVIII e início do século XIX, ou seja, término da sociedade monárquica e começo da sociedade estatal objetiva governar tanto os indivíduos, através de procedimentos disciplinares, quanto a população em geral. O nascimento da biopolítica ocorre no sistema do Liberalismo, um exercício do governo que busca maximizar seus efeitos e reduzir seus custos. Através de uma tecnologia de poder, a governamentalidade tem como foco a população, conjunto de indivíduos que são controlados com o objetivo de assegurar uma melhor gestão da força de trabalho dentro da sociedade capitalista (REVEL, 2005).

Em torno das disciplinas impostas ao corpo-máquina e do controle regulador no corpo-espécie desenvolveu-se a organização do poder sobre a vida. Na opinião de Machado (2008), o poder disciplinar age por meio da inscrição dos corpos em determinados espaços, do controle do tempo sobre eles, da vigilância contínua e da produção de saber através das práticas de poder. Nas palavras de Machado, a disciplina é "uma técnica, um dispositivo, um mecanismo, um instrumento de poder [...]. É o diagrama de um poder que não atua no exterior, mas trabalha o corpo dos homens, manipula seus elementos, produz seu comportamento [...]" (p. 17).

No século XX, segundo Foucault (2005, p. 301), é considerável a importância da Medicina, "dado o vínculo que estabelece entre as influências científicas sobre a população e sobre o corpo". A medicina é um saber-poder que incide ao mesmo tempo sobre o corpo e sobre a população e que vai ter efeitos disciplinares e regulamentadores. A norma é o que pode tanto se aplicar a um corpo que se quer disciplinar quanto a uma população que se quer regulamentar.

Ao governar os sujeitos para que tenham uma vida melhor, com saúde e mais longa, a biopolítica faz com que eles produzam mais para a sociedade. $O$ sujeito tem que ser saudável para que seja produtivo socialmente. Desta forma, o poder também é positivo. Na sociedade monárquica, o poder emanava de uma única pessoa, o rei, e a questão central era a morte. $\mathrm{O}$ rei decidia quem iria morrer e não se questionava esse poder que era dado apenas a ele. Na sociedade atual isso não acontece. Hoje, os governantes querem preservar a vida. A governabilidade gira em torno da 
longevidade dos sujeitos. Não é à toa que a população mundial alcançou o patamar de 7 bilhões de habitantes. Há uma política globalizada para preservare, consequentemente, prolongar a vida. Isso faz com que os sujeitos sejam produtivos por mais tempo e também consumam cada vez mais.

Além do princípio da disciplina, ele descreveu a modernidade por meio de outro conceito, o de biopoder, também fundamental para que se possa abordar o corpo na modernidade. A disciplina recortou o corpo na sua individualidade para a reprodução dos exercícios e a produção dos corpos dóceis, enquanto o biopoder tomou o corpo no conjunto da população, exercendo um exercício de governo da vida por meio do controle dos nascimentos, das mortes, das práticas sexuais, além da moradia, da instrução, do trabalho, tomando os corpos em conjunto e aplicando-lhes as leis e normas (FOUCAULT, 2005, p. 293). Tanto quanto para as disciplinas, o nascimento do "corpo organismo" também foi fundamental para o aparecimento do biopoder, que tomou o conjunto dos corpos dando-lhes a face de uma população. Assim, a disciplina sobre os corpos individuais e o biopoder como um poder sobre a vida das populações compuseram, conjuntamente, todo um arsenal de aparatos dentro das instituições que sustentaram a sociedade moderna e uma forma específica de governo, chamada por Foucault de governamentalidade, que funcionou até bem pouco tempo. Nos anos 80, ele afirmou que estávamos deixando de ser modernos e anunciou que o próximo século seria deleuziano.

\section{Corpo e sociedade de controle}

Na contemporaneidade, a maior atenção dedicada ao corpo e às práticas relacionadas a ele apenas reforça e solidifica seu controle e dominação. É paradoxal a relação entre corpo e poder: quanto maior a atenção sobre o corpo, maior é o controle sobre ele.

$\mathrm{Na}$ tentativa de compreender a crise da modernidade podemos seguir a sugestão de Foucault, isto é, recorrer às análises de Deleuze sobre a "sociedade de controle". Para o autor, Foucault demonstrou que os limites temporais do modelo disciplinar estavam claramente demarcados e que este havia entrado em crise na segunda metade do século XX. Deleuze (1992) demonstra a crise disciplinar por meio da crise dos modos de confinamento como a prisão, o hospital, a fábrica, a escola e a família.

Do ponto de vista do autor, os confinamentos da disciplina eram moldes produtores de subjetividades, ao passo em que os controles são uma "modulação", isto é, uma moldagem que pode ser transformada continuamente, produzindo uma situação flexível da subjetividade que é a chave do controle. As antigas instituições, como a fábrica, o hospital, a prisão e a escola se transformaram em empresas, modificando a gramática que havia sido produzida pela sintaxe disciplinar, que se torna obsoleta na 
sociedade de controle. Ao analisarem o conceito deleuziano de sociedade de controle, Negri e Hardt (2004) consideram que a sociedade de controle pode também ser compreendida como uma intensificação das disciplinas.

O corpo e a vida são matéria farta para o exercício da disciplina e do biopoder, produzindo corpos dóceis, na sociedade disciplinar. A sociedade de controle, como um novo modelo de sociedade ou como a intensificação das disciplinas, também tem o corpo como substrato de sua produção subjetiva. O que é o corpo no interior da sociedade de controle? Neste contexto há uma intensificação dos controles sobre o corpo, traduzidos em uma ampliação e transformação da biopolítica.

Trata-se do surgimento da ideia de que há corpos que podem desaparecer para que outros possam viver seguramente, em um mundo controlado pelas novas modalidades tecnológicas. Por outro lado, há também novas formas corporais de resistência e transgressão, as quais se apropriam das novas tecnologias e das artes, por exemplo. Uma gestão autônoma da vida e do corpo é uma empreitada transgressora no interior das tecnologias de controle. Para Deleuze, "os anéis da serpente são ainda mais complicados que os buracos da toupeira” (DELEUZE, 1992, p. 225-6).

No século XX, passamos de uma sociedade disciplinar para uma sociedade de controle. Para Deleuze, a sociedade midiática é uma sociedade de controle. Essa sociedade aperfeiçoou as técnicas de controle, que agem quase despercebidas, de modo bastante natural, de maneira sutil, principalmente na publicidade. Na escola, por exemplo, uma técnica de controle é a lista de frequência, que verifica cotidianamente a presença ou não dos alunos na sala de aula. Na opinião do autor, o controle é mais nefasto do que a disciplina. Assim, o século XX foi disciplinador e o século XXI é controlador.

Atualmente, há um discurso mercantil, de base econômica e mercadológica, na mídia, que leva o sujeito a consumir comida calórica (fast food) para que seja necessário o uso de produtos ligth e/ou diet, ou então fazer plásticas para ter o corpo cultuado na publicidade desses produtos. Há um investimento político dos corpos nos anúncios publicitários do tipo "como perder $7 \mathrm{~cm}$ em 10 dias", "emagreça 5 quilos em dois meses". Assim, o sujeito é controlado sem perceber. Ele vai fazendo transformações no corpo para entrar na ordem do discurso midiático: "seja magro!". Esse discurso reafirma o ponto de vista de Foucault (2008, p. 147): "encontramos um novo investimento que não tem mais a forma de controle-repressão, mas de controle-estimulação: 'Fique nu... mas seja magro, bonito, bronzeado!"”

Não se restringindo mais aos círculos institucionais, as disciplinas refinaram-se, expondo-se como táticas flexíveis de controle e indiciando, conforme Deleuze (1992, p. 216), a reformulação das sociedades disciplinares em sociedades de controle, "que 
funcionam não mais por confinamento, mas por controle contínuo e comunicação instantânea". Com esta transição, intensificou-se uma biopolítica, que, de acordo com Revel (2005, p. 27), "representa uma grande Medicina Social $\square$ que se aplica à população a fim de governar a vida", a fim de impor as formas de "bem-estar social", inserindo a vida no campo do poder.

O biopoder, segundo Gregolin (2007, p. 19-20), "materializa-se no governo de si: o sujeito deve autocontrolar-se, modelar-se a partir das representações que lhe indicam como deve (e como não deve) ser o seu corpo". Isso remete ao que Foucault denomina governamentalidade, o governo de si e do outro por meio de técnicas que produzem identidades.

Há uma moldagem do corpo, que ocorre como uma tática flexível de controle, caracterizando, conforme Deleuze (1992, p. 216), a transição da sociedade disciplinar para a sociedade de controle. A mídia exerce esse controle contínuo, intensificado por uma biopolítica, que se repete sem cessar. O corpo é concebido como "uma realidade biopolítica" (FOUCAULT, 2008), como alvo de uma política de "controle-estimulação" que objetiva trabalhá-lo, produzi-lo, expondo aos sujeitos as maneiras de pensar e de agir "adequadas" para a sociedade e incitando-os à interiorização e à incorporação destas convenções idealmente construídas.

As novas tecnologias de gerenciamento da vida e do corpo são corolários de transformações profundas na forma de produção de conhecimento sobre a vida. Com o advento da Biologia Molecular e das biotecnologias, o conceito de vida se transformou em um código a ser desvendado, o DNA. A partir dessa nova categorização da vida, o corpo passou a ser a decorrência de um conjunto de informações que devem ser melhoradas e reproduzidas (ORTEGA, 2008).

Assim, a nova gestão do corpo é a administração do corpo saudável, construído por meio de uma alimentação cientificamente balanceada, exercícios físicos controlados, o controle do estresse e da felicidade, específicos para cada singularidade molecular. O controle genético do corpo ainda faz parte de um conjunto de análises futurológicas, embora já existam como rotina em consultórios médicos os exames de detecção de certos tipos de cânceres, como, por exemplo, um tipo específico de câncer de mama. Na presença de marcadores genéticos em exames de sangue, algumas mulheres já realizaram mastectomização preventiva, isto é, a extração das mamas como prevenção, em nome da saúde perfeita. A ideia do risco para a saúde e para o corpo saudável começa a tomar contornos importantes para o biopoder, na medida em que o cuidado para com a vida, já pensado por Foucault como definidor da modernidade, se desloca em virtude da tecnologia.

A biopolítica incidirá sua ação no seu objeto de regulação política: a população. A conduta agora não é mais do homem 
como indivíduo disciplinado, mas da população como contingente economicamente regulada. O efeito disso será a construção de uma sociedade que trabalha suas tecnologias de poder no sentido de fazer da ação coletiva, uma rentabilidade cada vez maior. No final do século XIX e início do século XX, o Estado preparou, com toda a sutileza e aprendizado das antigas formas de poder, o que estamos vivenciando cada vez mais no tecido social e dentro de um processo inconsciente: mais do que disciplinar e vigilante, a sociedade se caracteriza por um controle virtual do indivíduo e da população. As novas tecnologias do século XXI (audiovisuais, internet, cartões de crédito etc.), empreendendo o deslocamento das relações de poder para o campo virtual, caracterizam a nova forma do poder: a sociedade de controle.

Ao ponderar sobre esse tipo de sociedade, Gregolin afirma que

na sociedade de controle (que se desenvolve nos limites da modernidade), os mecanismos tornam-se cada vez mais "democráticos", cada vez mais interiorizados pelos sujeitos: esse poder é exercido por máquinas que organizam o cérebro (redes de informação) e os corpos (em sistemas de bem-estar, atividades monitoradas etc.) (GREGOLIN, 2007, p. 18).

Segundo Deleuze, não vivenciamos mais apenas o confinamento e a vigilância, que sequestram a vida do indivíduo e da massa à qual ele pertence, mas o controle, que modula ilimitadamente a vida. Hardt e Negri (2004) caracterizam a sociedade de controle como um cenário propício e indispensável para a formação e o desenvolvimento do arquétipo representado pela figura do Império e de toda a sua sistemática de regulação e justificação. Para os autores, a sociedade de controle deve ser entendida

como aquela (que se desenvolve nos limites da modernidade e se abre para a pós-modernidade) na qual mecanismos de comando se tornam cada vez mais 'democráticos', cada vez mais imanentes ao campo social, distribuídos por corpos e cérebros dos cidadãos. [...] A sociedade de controle pode [...] ser caracterizada por uma intensificação e uma síntese dos aparelhos de normalização de disciplinariedade que animam nossas práticas diárias e comuns, mas, em contraste com a disciplina, esse controle estende bem para fora os locais estruturados de instituições sociais mediante redes flexíveis e flutuantes (HARDT e NEGRI, 2004, p. 42-3).

\section{Palavras finais}

A imagem do corpo se tornou imprescindível, de modo que podemos afirmar que hoje o eu é o corpo. A subjetividade foi reduzida ao corpo, sua imagem, saúde, juventude e longevidade. O predomínio da dimensão corporal na constituição identitária permite sugerir, como fez Ortega (2005), a existência de uma "bioidentidade". Como afirma o autor, se, por um lado, para 
construir a "bioidentidade", é preciso se submeter a uma bioascese, ou seja, adequar o corpo às normas científicas existentes sobre a saúde, os exercícios físicos, a longevidade, a nutrição; por outro, é preciso ajustar o corpo às normas e padrões da sociedade do espetáculo. Não possuímos uma visão pura do nosso próprio corpo, mas somente uma "interpretação" acerca dele, bem como dos outros corpos.

Assim como se modificam historicamente as condições concretas de produção social, política e econômica dos corpos, mudam-se de forma igualmente histórica as condições da sua estetização. É redundante afirmar que as concepções e padrões estéticos se transformam ao longo da história. Basta notar que o século XX foi muito rico em diversidade estética, fazendo, literalmente, desfilar na passarela da mídia sucessivas modas, recorrências, variados padrões corporais e também tecnologias, muitas delas médicas, de produção e modelagem dos corpos segundo uma estética corporal que se modifica historicamente. Não é o corpo que muda ao longo do tempo, mas sim o nosso olhar/ discurso sobre ele.

\begin{abstract}
In this paper, we reflect about the biopolitics of the body through the effects of meanings produced by the mechanisms of power / knowledge in the discourse of self-care and how the disciplinary and control devices act on the body presented in media.
\end{abstract}

Keywords: biopolitics; body; control.

\title{
REFERÊNCIAS
}

COURTINE, Jean-Jacques. O corpo anormal - História e antropologia culturais da deformidade. In: CORBIN, A.; COURTINE, J-J.; VIGARELLO, G. (Orgs.). História do Corpo: 3. As mutações do olhar. O século XX. Tradução Ephraim Ferreira Alves. Petrópolis, RJ: Vozes, 2008, p. 253-340.

DÉBORD, Guy. Comentários sobre a sociedade do espetáculo. In: . A sociedade do espetáculo. Rio de Janeiro: Contraponto, 1997.

DELEUZE, Gilles. Post-scriptum sobre as sociedades de controle. In: Conversações. Tradução Peter Pál Pelbart. São Paulo: Editora 34, 1992. p. 221-224.

DREYFUS, H,; RABINOW, P. Michel Foucault. Uma trajetória filosófica. $2^{\mathrm{a}}$. ed. Tradução Vera Portocarrero e Gilda Gomes Carneiro. Rio de Janeiro: Forense Universitária, 2010. 
FOUCAULT, Michel. Aula de 17 de março de 1976. In: Em defesa da sociedade. Tradução Maria E. Galvão. São Paulo: Martins Fontes, 2005, p. 285-315. . As palavras e as coisas. São Paulo. Martins Fontes, 2007. A arqueologia do saber. $7^{\text {a }}$. ed. Tradução Luiz Felipe Baeta Neves. Rio de Janeiro: Forense Universitária, 2008. Vigiar e punir: nascimento da prisão. $36^{\text {a }}$. ed. Tradução de Raquel Ramalhete. Petrópolis, RJ :Vozes, 2009.

GREGOLIN, Maria do R. V. Análise do Discurso e mídia: a (re) produção de identidades. Dossiê. Comunicação, Mídia e Consumo. São Paulo, vol. 4, no 11, nov. 2007, p. 11-25.

HARDT, M.; NEGRI, A. Produção biopolítica. Império. $6^{\mathrm{a}}$. ed. Rio de Janeiro: Record, 2004. p. 41-60.

MACHADO, Roberto. Por uma genealogia do poder. In: FOUCAULT, M. Microfísica do poder. 25a . ed., Tradução Roberto Machado. Rio de Janeiro: Graal, 2008.

ORTEGA, Francisco. Da ascese à bio-ascese ou do corpo submetido à submissão ao corpo. In: RAGO, M.; VEIGA-NETO. A. As imagens de Foucault e Deleuze ressonâncias nietzschianas. $2^{\mathrm{a}}$. ed. Rio de Janeiro: DP\&A, 2005. p.139-173.

. O corpo incerto: corporeidade, tecnologias médicas e cultura contemporânea. Rio de Janeiro: Garamond, 2008.

VIGARELLO, Georges. A História da beleza: o corpo e arte de se embelezar, do renascimento aos dias de hoje. Tradução Léo Schlafman. Rio de Janeiro: Ediouro, 2006. 